\title{
Aplikasi Mikrofon Ambisonik untuk Pengukuran Kebisingan
}

\author{
Anugrah Sabdono Sudarsono ${ }^{1}$
}

\begin{abstract}
In soundscape study, acoustic environment recording usually conducted using ambisonic microphone which record the sound from several direction simultaneously. Sonic environment analysis also includes the measurement of environmental noise which taken using Sound Level Meter. The measurement sometimes conducted in crowded urban area which is hard to take the recording systems and sound level meter at the same times.

This study tries to analyse the performance of ambisonic microphone for noise measurement. The experiment is conducted by comparing the response two microphones (ambisonic and measurement microphone) in diffuse field. The experiment data shows that the frequency response of the ambisonic microphone is similar to the type 1 measurement microphone with 2,80 dB on average. The overall sound level measurement shows that the difference is not significant. The results indicate that the ambisonic microphone can be used for general noise measurement.
\end{abstract}

KEYWORDS: Ambisonic Microphone, Measurement Microphone, Noise Measurement

ABSTRAK: Salah satu metode yang digunakan untuk analisis soundscape adalah dengan menggunakan rekaman (dibuat dengan mikrofon ambisonik) dan dengan pengukuran kebisingan yang dilakukan secara bersamaan. Analisis lingkungan sonik berbasis soundscape ini ini membutuhkan juga data terkait kebisingan dari lingkungan yang diambil dengan menggunakan Sound Level Meter (SLM). Permasalahan yang muncul adalah seringali pengukuran dilakukan pada daerah urban yang ramai yang tidak memungkinkan untuk membawa alat perekam suara dan SLM secara bersamaan.

Penelitian ini bertujuan untuk menganalisis kinerja mikrofon jenis ambisonik untuk pengukuran kebisingan. Dari hasil pengujian pada medan difus menunjukkan bahwa respon frekuensi mikrofon ambisonik ini mirip dengan respon pengukuran dari mikrofon pengukuran tipe 1 walaupun terdapat perbedaan rata-rata sebesar 2,80 dB. Pengukuran kebisingan secara keseluruhan juga menunjukkan bahwa hasil pengukuran tingkat tekanan suara dari mikrofon ini tidak berbeda secara signifikan dengan hasil pengukuran tingkat tekanan suara dari mikrofon pengukuran. Hasil ini menunjukkan bahwa mikrofon ambisonik dapat digunakan untuk pengukuran kebisingan secara umum.

KATA KUNCI: Mikrofon Ambisonik, Mikrofon Pengukuran, Pengukuran Kebisingan

\section{PENDAHULUAN}

$\mathrm{S}$ alah satu metode analisis soundscape adalah dengan cara mereproduksi rekaman lingkungan sonic [1]. Pada penelitian ini, rekaman lingkungan sonic biasanya dilakukan dengan mikrofon ambisonik [2]. Mikrofon ambisonik adalah mikrofon yang terdiri dari empat buah kapsul dengan keluaran empat buah sinyal yang dinamakan sinyal $\mathrm{W}, \mathrm{X}, \mathrm{Y}$, dan Z [3]. Sinyal $\mathrm{W}$ adalah sinyal suara yang ditangkap dari segala arah (omnidireksional) sementara sinyal X, Y, dan Z adalah sinyal yang ditangkap pada sumbu X, Y, dan Z (output bidireksional). Diagram polar dari mikrofon ambisonik ini ditunjukkan pada Gambar 1.

Penelitian soundscape berusaha untuk menjelaskan bagaimana persepsi manusia terhadap lingkungan sonic [4]. Pengukuran dalam penelitian ini dilakukan dengan dilakukan secara sekaligus yaitu dengan pengukuran subjektif dan objektif. Pengukuran subjektif biasa dilakukan dengan menggunakan kuisioner untuk megetahui bagaimana persepsi manusia dan pengukuran objektif salah satunya dilakukan dengan mengambil data tingkat tekanan suara. Pada saat survey biasanya diambil juga rekaman lingkungan sonik dengan menggunakan mikrofon ambisonic.

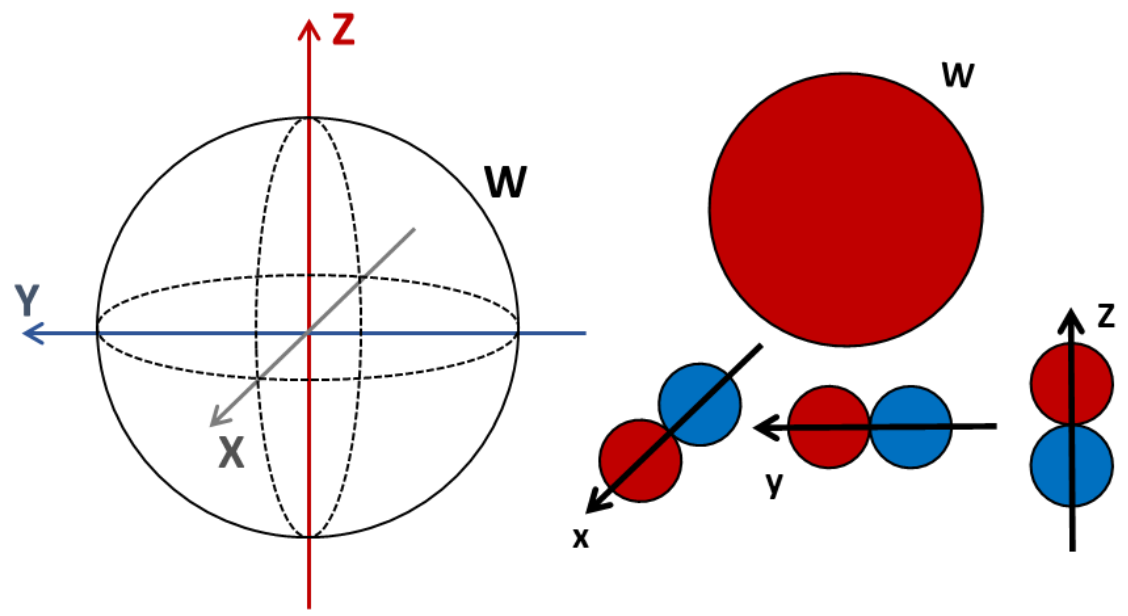

Gambar 1 Diagram Polar Mikrofon Ambisonik

Output dari mikrofon ambisonik (4 output) ini direkam secara simultan dengan alat perekam. Pada saat yang bersamaan umumnya diukur kondisi kebisingan dengan Sound Level Meter atau sistem pengukuran kebisingan.

${ }^{1}$ Fakultas Fisika Universitas Teknologi Bandung 
Permasalahan yang muncul adanya penggunaan alat yang banyak membuat survey harus dilakukan oleh beberapa orang sekaligus. Salah satu alternatif yang dapat digunakkan adalah dengan mengolah data pengukuran kebisingan dari rekaman mikrofon ambisonic, terutama dari sinyal W yang menangkap suara dari segala arah.

Pada penelitian ini dilakukan evaluasi apakah sinyal omnidireksional dari mikrofon ambisonik dapat digunakan untuk mengambil data tingkat tekanan suara. Evaluasi dilakukan dengan membandingkan respon frekuensi dan hasil pengukuran dari mikrofon ini dengan mikrofon pengukuran pada medan difus.

\section{EKSPERIMEN}

Eksperimen dilakukan di ruangan dengung Institute Teknologi Bandung yang ditunjukkan seperti Gambar 2 yang memenuhi standar ISO 354-2003. Ruangan ini adalah ruangan dimana suara dipantulkan sehingga waktu dengung ruangan menjadi tinggi dan menciptakan medan suara difus di dalamnya.

Konsep kalibrasi berbasis medan difus ini diperkenalkan oleh heler dkk dan merupakan alternative kalibrasi mikrofon yang memiliki ukuran berbeda dengan mikrofon pengukuran [5]. Kalibrasi dengan konsep ini dilakukan dengan membangkitkan suara para tingkat tekanan suara tertentu secara difus (suara datang dari segala arah) dan rekaman suara tersebut kemudian dijadikan referensi untuk mengetahui tingkat tekanan suara dari rekaman yang dibuat. Skema pengukuran ditunjukkan pada Gambar 3.

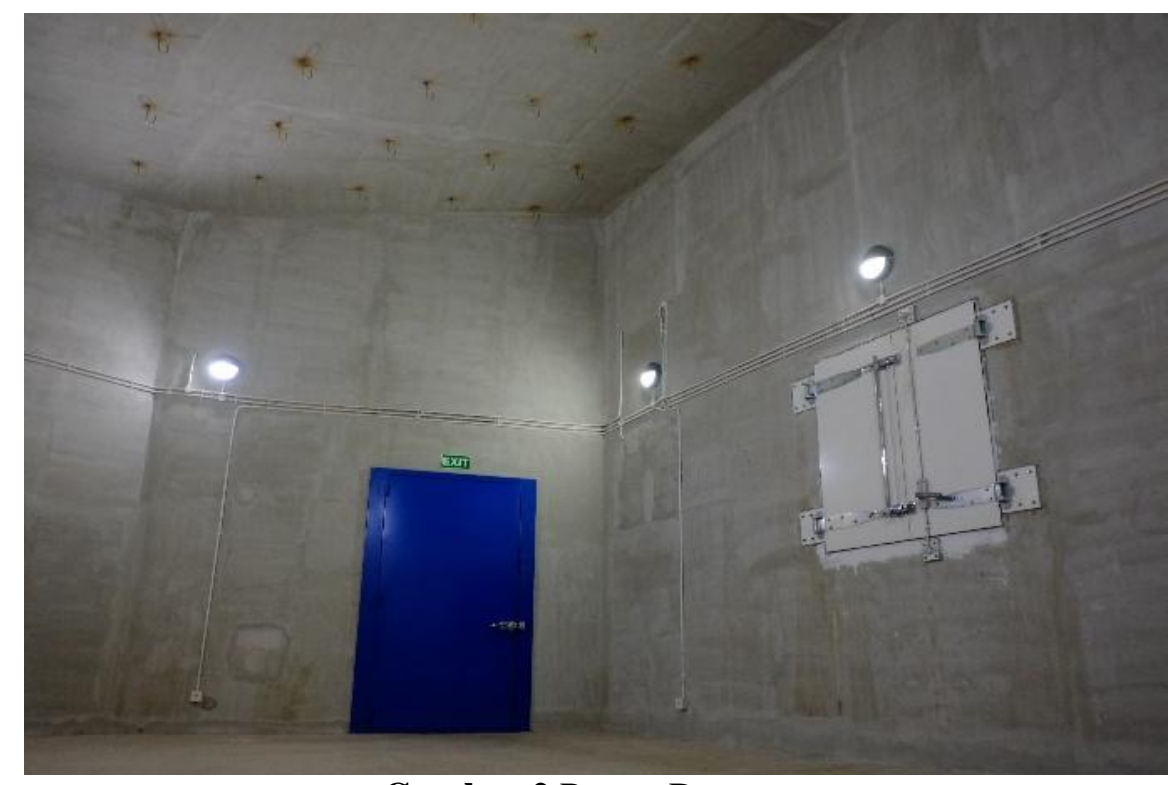

Gambar 2 Ruang Dengung

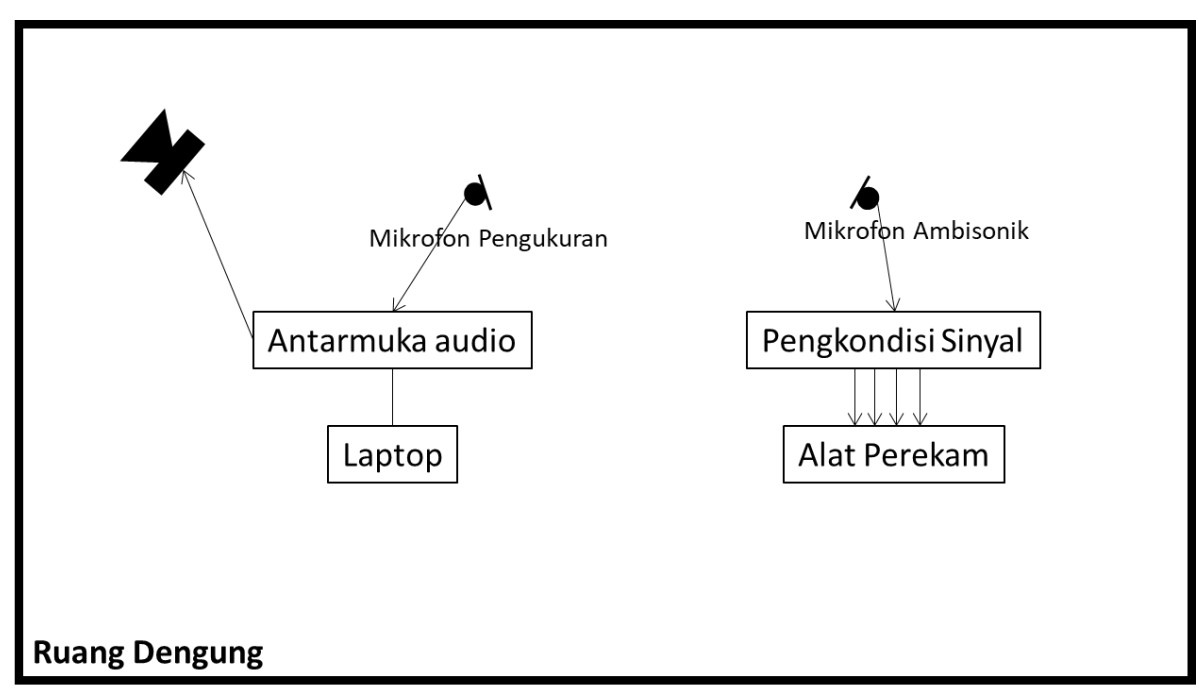

Gambar 3 Skema Pengukuran dalam Ruang Dengung

Eksperimen dilakukan dengan membunyikan sinyal white noise di dalem ruang dengung dengan tingkat kekerasan suara sebesar $80 \mathrm{~dB}$ dan $85 \mathrm{~dB}$. Suara tersebut kemudian diukur dan direkam dengan menggunakan mikrofon pengukuran yang terhubung dengan perangkat antarmuka audio (ditunjukkan pada Gambar 4) yang terhubung pada sebuah laptop. Pada saat yang bersamaan, suara yang ada di dalam ruang dengung direkam dengan mikrofon ambisonik Soundfield ST 250 yang ditunjukkan pada Gambar 5. 


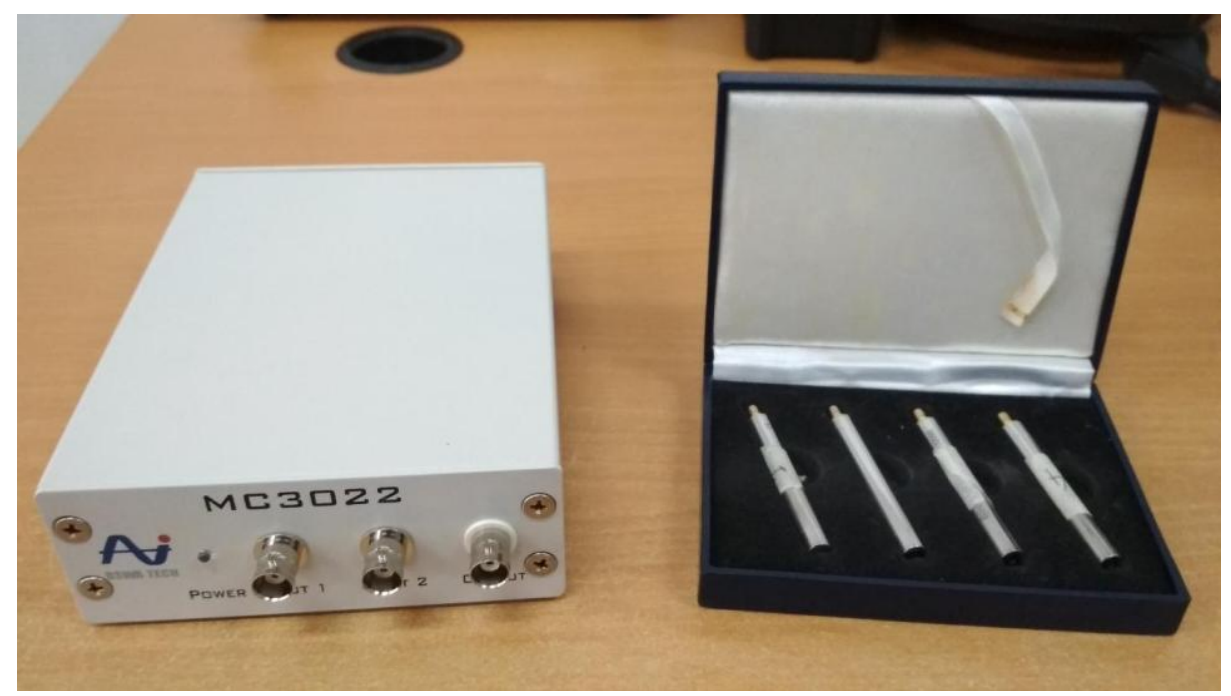

Gambar 4 Antarmuka Audio dan mikrofon pengukuran

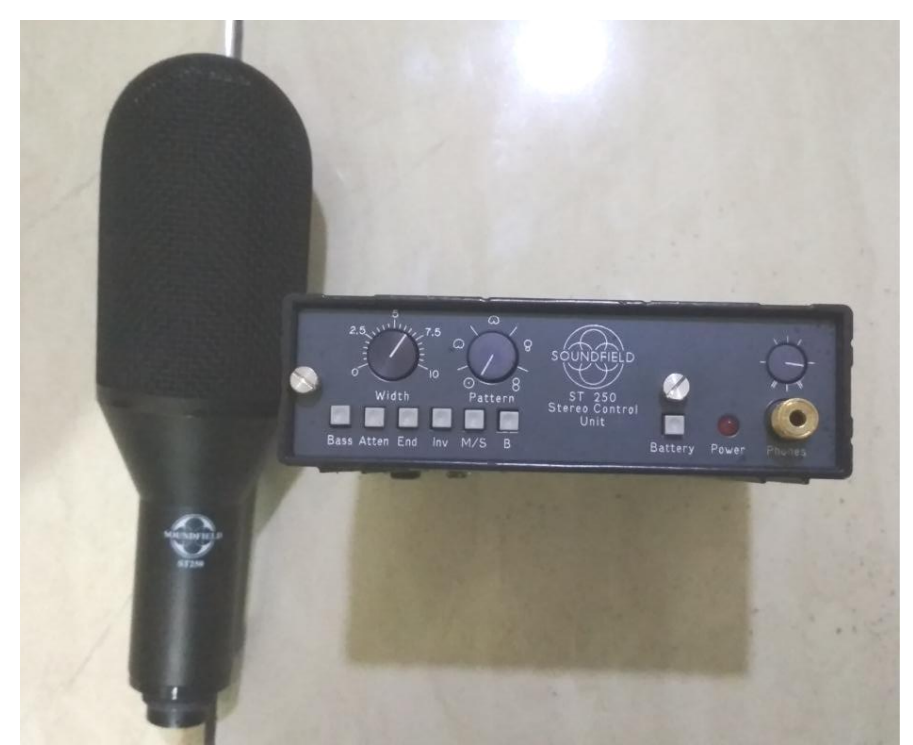

Gambar 5 Mikrofon Ambisonik dan Pengkondisi Sinyalnya

Mikrofon ambisonik yang digunakan ini memberikan keluaran 4 buah sinyal (W, X, Y dan Z) yang direkam secara simultan dengan menggunakan alat perekam Tascam DR-70 D yang ditunjukkan pada Gambar 6. Analisis dilakukan dengan dua cara yaitu dengan membandingkan respon frekuensi dari kedua buah mikrofon dan nilai pengukuran

kebisingan selama 5 menit. Pengukuran selama 5 detik ini dilakukan dengan mencuplik data setiap satu detik.

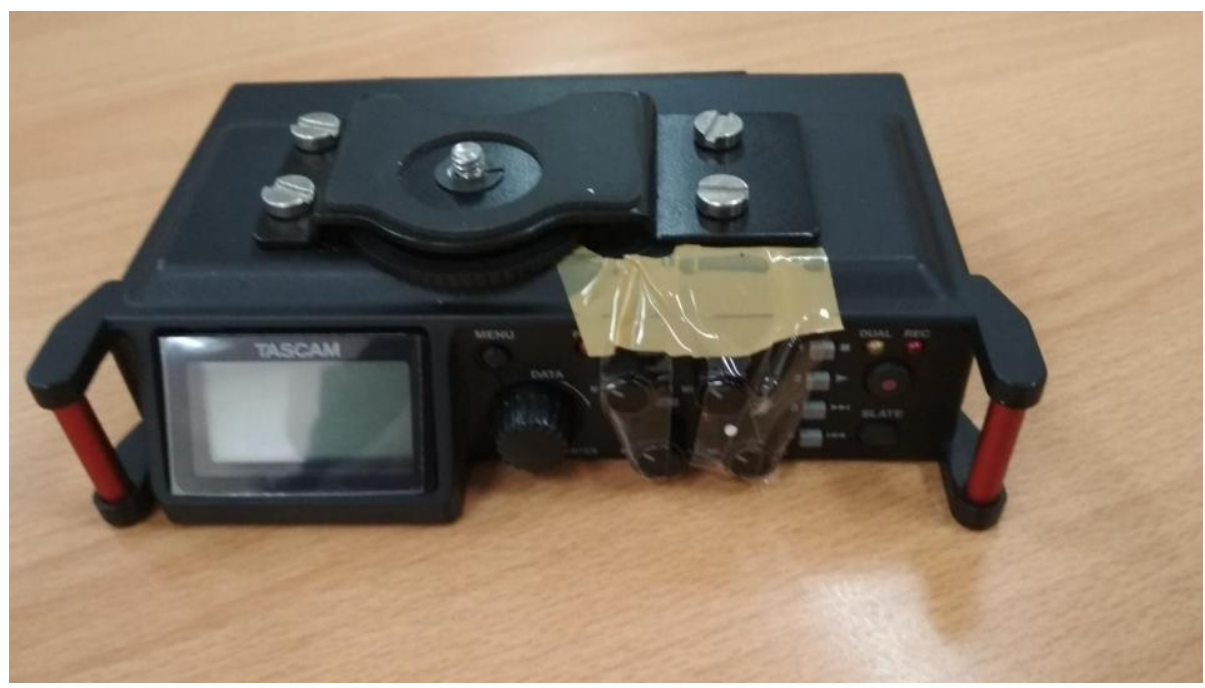


Gambar 6 Alat Perekam Audio Tascam DR-70D

\section{ANALISIS}

Hasil pengukuran kebisingan menunjukkan profil kebisingan yang mirip antara mikrofon pengukuran dan mikrofon ambisonik saat mengukur medan difus berupa white noise pada 80 dan $85 \mathrm{~dB}$. Respon frekuensi kedua mikrofon pada medan difus sebesar 80 dan $85 \mathrm{~dB}$ ditunjukkan pada Gambar 7 dan Gambar 8 . Untuk $80 \mathrm{~dB}$

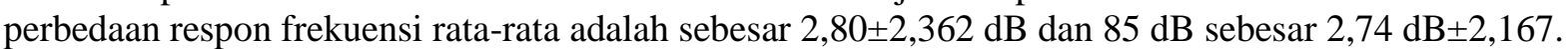

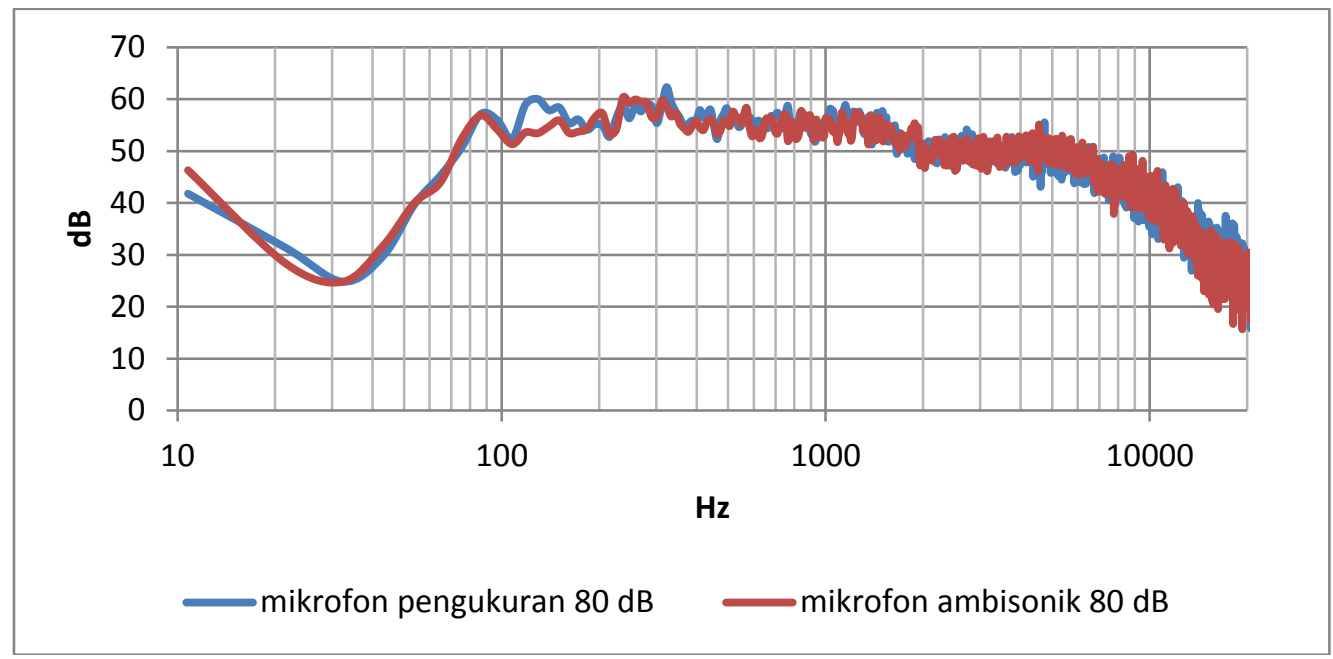

Gambar 7 Respon Frekuensi Mikrofon Pengukuran dan Mikrofon Ambisonik pada $80 \mathrm{Db}$

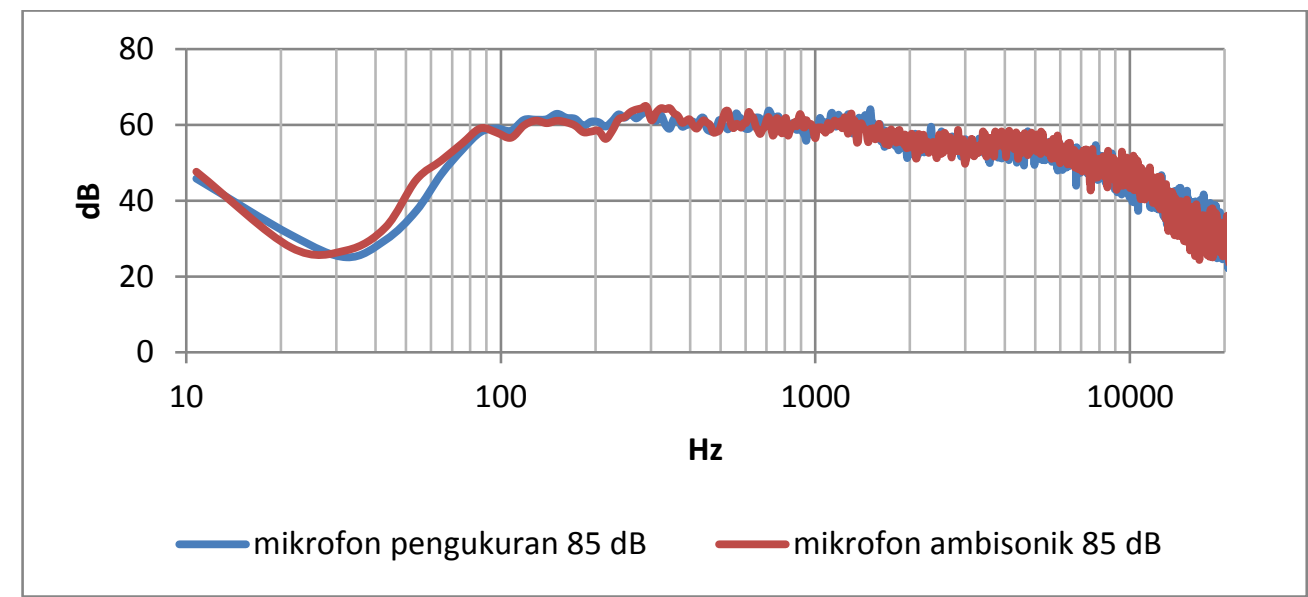

Gambar 8 Respon Frekuensi Mikrofon Pengukuran dan Mikrofon Ambisonik pada 85 dB

Pengukuran respon frekuensi menunjukkan adanya galat yang cukup besar yang muncul pada frekuensi yang berbeda. Hal ini menunjukkan bahwa mikrofon ambisonik ini tidak dapat dilakukan untuk melakukan pengukuran secara detil walaupun masih dapat digunakan untuk melihat profil kebisingan.

Pengukuran kebisingan pada medan bebas dilakukan pada tingkat tekanan suara konstan sebesar 80 dan 85 dB. Hasil pengukuran selama 5 menit menunjukkan nilai kebisingan yang tidak berbeda secara signifikan $(\mathrm{p}=$ 0,968 pada pengukuran $80 \mathrm{~dB}$ dan $\mathrm{p}=0,202$ pada pengukuran $85 \mathrm{~dB}$ ) pada pengukuran dengan mikrofon pengukuran dan mikrofon ambisonik seperti ditunjukkan pada Gambar 9 dan 10. Hasil pengukuran menunjukkan nilai rata-rata yang tidak banyak berbeda, yaitu $0 \mathrm{~dB}$ pada pengukuran $80 \mathrm{~dB}$ dan $0,06 \mathrm{~dB}$ pada pengukuran $85 \mathrm{~dB}$ 


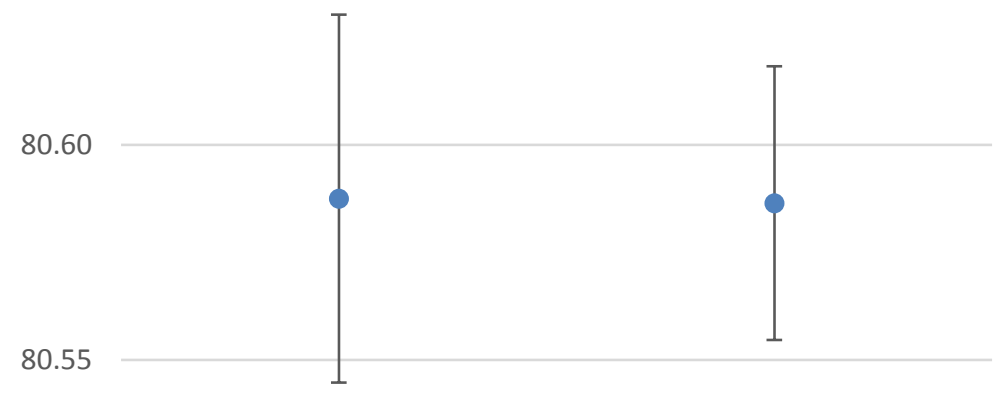

\begin{tabular}{|c|c|c|}
\hline 80. & mikrofon pengukuran & mikrofon ambisonic \\
\hline - nilai rata-rata & 80.59 & 80.59 \\
\hline
\end{tabular}

Gambar 9 Hasil Pengukuran pada sinyal "White Noise" pada $80 \mathrm{~dB}$

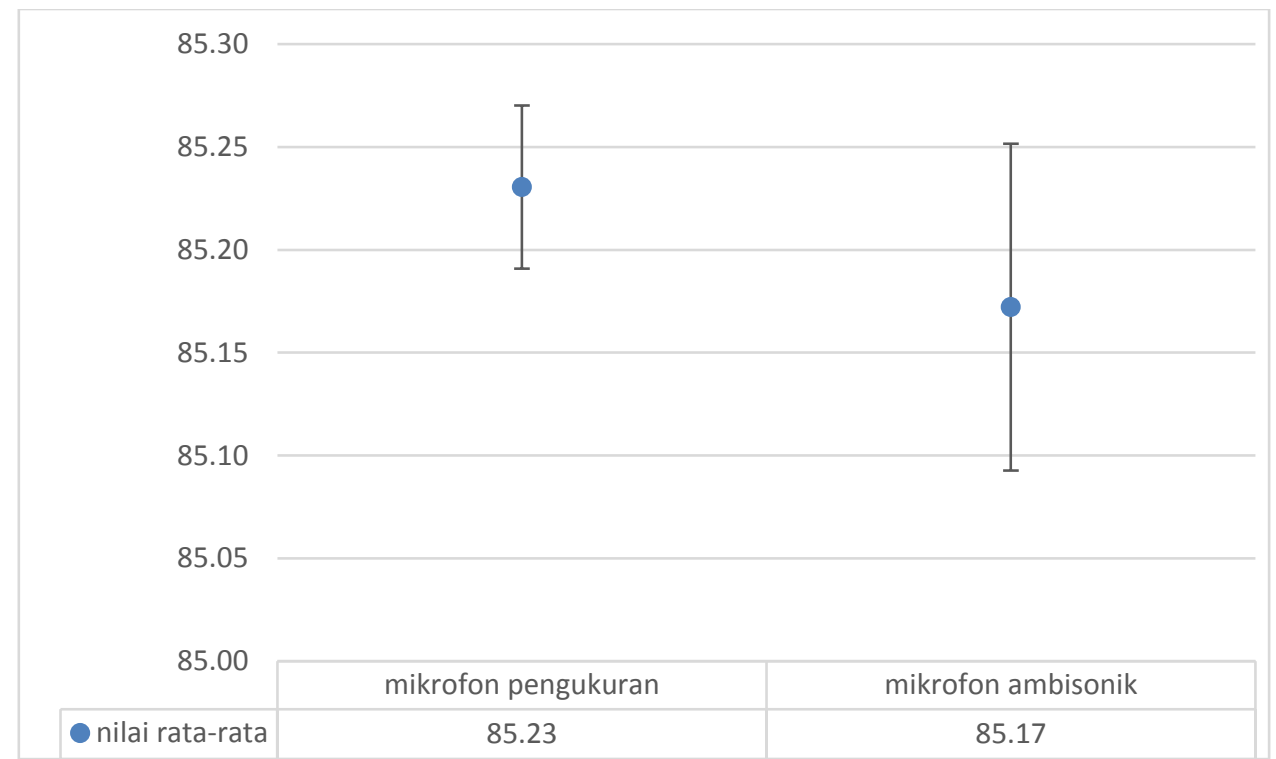

Gambar 10 Hasil Pengukuran pada sinyal "White Noise" pada $85 \mathrm{~dB}$

Hasil pengukuran Leq dari dua kondisi pengukuran ( 80 dan $85 \mathrm{~dB})$ menunjukkan sedikit perbedaan sebesar $0,05 \mathrm{~dB}$ pada pengukuran $85 \mathrm{~dB}$ seperti ditunjukkan pada Tabel 1 . Pengukuran pada $80 \mathrm{~dB}$ menunjukkan tidak ada perbedaan nilai Leq dari kedua jenis mikrofon.

Tabel 1. Hasil Pengukuran Leq

\begin{tabular}{|l|l|l|l|l|}
\hline \multirow{2}{*}{ Pengukuran } & \multicolumn{2}{|c|}{$80 \mathrm{~dB}$} & \multicolumn{2}{c|}{$85 \mathrm{~dB}$} \\
\cline { 2 - 5 } & Mikrofon Pengukuran & Mikrofon Ambisonik & Mikrofon Pengukuran & Mikrofon Ambisonik \\
\hline \multirow{2}{*}{ Leq } & 80,59 & 80,59 & 85,23 & 85,18 \\
\hline
\end{tabular}




\section{KESIMPULAN}

Hasil pengukuran menunjukkan bahwa respon frekuensi mikrofon ambisonik mirip dengan mikrofon pengukuran tipe 1 dengan perbedaan rata-rata sebesar $2.80 \mathrm{~dB}$. Pengukuran bising secara keseluruhan menunjukkan perbedaan yang tidak signifikan antara kedua mikrofon dengan perbedaan $0,05 \mathrm{~dB}$. Hasil ini mengidikasikan bahwa mikrofon ambisonik dapat digunakan untuk pengukuran kebisingan secara umum.

\section{DAFTAR PUSTAKA}

[1] F. Aletta, J. Kang, Ö. Axelsson, Landscape and Urban Planning Soundscape descriptors and a conceptual framework for developing predictive soundscape models, Landsc. Urban Plan. 149 (2016) 65-74. doi:10.1016/j.landurbplan.2016.02.001.

[2] A.S. Sudarsono, Y.W. Lam, W.J. Davies, The effect of sound level on perception of reproduced soundscapes, Appl. Acoust. 110 (2016) 53-60. doi:10.1016/j.apacoust.2016.03.011.

[3] K. Ferrar, Soundfield Microphone: Design and development of microphone and control unit, Wirel. World. (1979) 48-50. http://www.ai.sri.com/ajh/ambisonics/wireless-world-farrar-10-1979.pdf.

[4] International Organization for Standarization, Draft BS ISO 12913-1 Acoustics - Soundscape. Part 1: Definition and conceptual framework, 44 (2013).

[5] A.J. Heller, E.M. Benjamin, Convention Paper 8711 the Diffuse-Field Response, in: Audio Eng. Soc. Conv. Pap. 8711, Audio Engineering Society, San Francisco, 2012: pp. 1-9. 